\title{
Mental health problems in the workplace: changes in employers' knowledge, attitudes and practices in England 2006-2010
}

\author{
Claire Henderson, Paul Williams, Kirsty Little and Graham Thornicroft
}

\section{Background}

In 2006 the Shaw Trust charity found high levels of ignorance and poor preparedness to deal with mental health problems among 480 senior employers in the UK. The UK government, non-governmental organisations and Time to Change (TTC) have since provided relevant assistance to employers.

\section{Aims}

To examine whether there have been improvements in mental health-related knowledge, attitudes and workplace practices among British senior employers between 2006 and 2010.

\section{Method}

A telephone survey was conducted of senior British employers ( $n=480$ in 2006 and $n=500$ in 2009 and 2010)

\section{Results}

An increased awareness of common mental health problems was detected. Employers continued to believe that job candidates should disclose a mental health problem, but became less likely to view colleagues' attitudes as a barrier to employing someone with such a problem. Formal policies on mental health and the use of workplace accommodations became increasingly common.

\section{Conclusions}

These results are consistent with those of the TTC national public attitudes and the viewpoint survey of service users between 2008 and 2010, which showed improved public attitudes to mental illness and a reduction in experiences of discrimination in employment.

\section{Declaration of interest}

G.T. has received grants for stigma-related research in the past 5 years from Lundbeck UK and from the National Institute for Health Research, and has acted as a consultant to the UK Office of the Chief Scientist.
The issue of mental health in British workplaces is currently the focus of much economic and social interest. In 2008 mental health problems accounted for an estimated 442000 cases of work-related illness annually, including 237000 new cases, with the loss of an estimated 13.5 million working days. ${ }^{1}$ Each person with a mental health problem was absent for an average of 30.6 days per year, more than for any other condition. ${ }^{1}$ Mental ill health accounts for a significant proportion of long-term absences from work and is responsible for many early retirements, estimated at $20 \%$ among National Health Service (NHS) employees for example. ${ }^{2}$ In 2006 the Shaw Trust, a UK not-for-profit organisation that works with employers, social services and people with disabilities to help such people find employment, commissioned a survey of employers and found high levels of ignorance and a lack of preparedness to deal with mental health problems in the workplace. Specifically, a third of those surveyed thought that none of their employees would have any form of mental ill health during their working life. ${ }^{3}$ Eighty per cent of the organisations surveyed did not have a specific mental health policy and the same proportion endorsed the view that more support was required to improve the way mental health is addressed in the workplace.

Recently work stressors have increased as a consequence of economic recession but sickness absence has fallen, suggesting employees fear taking time off and are present at work despite being unwell. ${ }^{4}$ Both the UK government and several non-governmental organisations have increased their efforts to assist employers in addressing mental ill health in the workplace. ${ }^{5-8}$ In 2009 the Time to Change (TTC) programme set up an online resource (Time to Challenge) for employers, people with mental health problems and their supporters to provide information about their rights and responsibilities and to show examples of good practice. ${ }^{9}$ To reassess the impact of both the increase in stressors and the increase in resources, we collaborated with the
Shaw Trust to repeat their 2006 survey in June 2009. ${ }^{10}$ Although knowledge about the prevalence of mental health problems had improved, as had stated willingness to offer reasonable adjustments, there was no increase in the existence of formal policies on workplace mental health. The aims of this study were therefore to document whether, as a result of initiatives such as those described above, there had been further changes between 2009 and 2010 (i.e. since the launch of TTC) in knowledge about and attitudes towards mental health among employers, and in their readiness to respond to employees with mental health problems; and to chart the overall direction of change between 2006 and 2010. We expected findings to inform communication with employers about the support they may need to create and maintain a healthy and diverse workplace with respect to mental health.

\section{Method}

The data collection methods for the original survey, conducted in March 2006, have been described previously. ${ }^{3}$ In brief, the 2006 survey consisted of telephone interviews using a 14-question survey focusing on employment of individuals with mental health problems and policies in place to assist these employees. These questions were derived after a literature review and qualitative research with a broad range of representatives from employer relations organisations, governmental and non-governmental organisations, researchers, business representatives and people with experience of mental health problems and employment. The original survey recruited a random sample of 500 chief executive officers (CEOs), managing directors or finance directors, with an additional sample of 50 human resources directors. The survey was incorporated into the annual Business Omnibus Telephone Research Survey, conducted by Continental Research. ${ }^{11}$ 
Employers were randomly selected using a weighted sampling design to ensure representation of both small ( $\$ 50000$ to $\mathfrak{E} 1$ million turnover; 300 interviews) and medium to large employers ( $>\mathfrak{£} 1$ million turnover; 200 interviews).

The repeat surveys, conducted in June 2009 and June 2010, were based on the 2006 survey methods. However, we wished to increase the proportion of human resources directors, especially for medium to large businesses in which the owner or managing director might have little or nothing to do with personnel responsibilities and thus be unable to answer questions about mental illness in the workforce. Therefore the sampling frame for the subsequent surveys differed slightly from 2006: approximately 300 small companies (1-50 employees) and 200 medium to large companies ( $>50$ employees) were to be included in the 2009 and 2010 samples. Within each of these groups we aimed to interview approximately 100 human resources directors; the interviewees were screened to ensure that they met the criteria of decision makers in relation to human resources matters. In both surveys only companies with one or more employee (excluding the interviewee) were recruited.

Because of its increased length (five additional questions were added) and the representation of human resources managers it was no longer possible to add the survey to the annual Business Omnibus Telephone Research Survey. It was therefore conducted as a stand-alone survey by means of computer-aided telephone interviews conducted by Teamsearch Market Research Services (www.teamsearchmr.co.uk). Employers were again sampled from all registered British businesses. This alteration also resulted in a small difference in the proportion of small to medium/large businesses sampled.

\section{Statistical analysis}

Where interviewees were asked to what extent they agreed with a statement, for the purposes of analysis responses were grouped into 'agreed' (including slightly agreed and strongly agreed) and 'did not agree' (including neither agree nor disagree, slightly disagree and strongly disagree). Owing to the slightly different sampling frames used in $2006 v$. the subsequent surveys, all survey questions were analysed using multiple regression analyses accounting for the size of the company (number of employees) and whether the interviewee was the human resources director (these are displayed as adjusted $P$-values). Each outcome was regressed using logistic, ordinal or multinomial logistic regression on year and adjustors for human resources director and company size. A Wald test was carried out to test the significance of the difference between 2009 and 2010. Percentages of positive responses are given for the raw data. Owing to the different sampling strategies between 2006 and the later years, adjusted probabilities were estimated from the regression models and these were reported in the same format to aid interpretation. Adjusted probabilities were adjusted by the average number of human resources directors and company size across the three years to allow comparisons between years to be made. Because of the large number of statistical tests made and the resulting risk of apparently significant results occurring by chance, we used a correction to the significance level (Holm-Bonferroni method). This decreased the acceptable $P$-value by a factor that depended on the number of tests within each question, thus retaining the familywise error rate. All analyses were performed using Stata version 11 for Windows XP.

\section{Results}

Eighty-one per cent of employers contacted agreed to take part in the 2010 survey, compared with $71 \%$ in 2009 and $93 \%$ in 2006 .
There was a significant difference in the sizes of the companies sampled in 2006 and 2009: 77\% of companies were small (1-50 employees) in 2006 compared with 60\% in $2009(P<0.001)$. The proportion of interviewees who were employed as human resources managers was also significantly different: $9 \%$ in 2006 compared with $49 \%$ in $2009(P<0.001)$. There was no significant difference between 2009 and 2010 .

\section{Knowledge of mental health in the workplace}

When asked what specific disorders they thought of when they heard the term 'mental health in the workplace' there was a general shift towards improved recognition of the more common mental health problems between 2006 and 2009, but no further improvement in 2010 (Table 1). In 2006 nearly a third (31\%) of employers erroneously thought that none of their employees would develop a mental health problem during their working life, compared with just 7\% in 2009 and 4\% in 2010. The adjusted odds ratio for reporting a higher frequency of mental health problems during their employees' working lives for 2010 compared with 2006 was 4.1 (95\% CI 3.2-5.3, $P<0.001$ ). However, there was again no evidence of further increases in the proportion of employers with a realistic estimate of employee mental health burden, e.g. $25 \%$ from 2009 to $2010\left(\chi^{2}(1)=4.2, P=0.04\right)$. Similarly, those interviewed in 2009 and 2010 were more likely to be aware of employees who currently had mental health problems compared with 2006 - adjusted ORs were 1.8 (95\% CI 1.3-2.6) for 2009 and 3.1 (95\% CI 2.2-4.2) for 2010 - but there was no significant difference between 2009 and 2010. Nearly half agreed that employees suffering from stress are able to work effectively at all time points.

\section{Mental health policies in the workplace}

In 2010 the likelihood of reporting a formal policy on stress and mental health in the workplace was significantly higher than in previous years: adjusted OR 1.6 (95\% CI 1.2-2.1) compared with 2006 (Table 2). Among those who knew that their company had a policy, there was no change over time in views regarding these policies. Agreement that the policy is well understood by managers (e.g. 77\% in 2010) and employees (66\% in 2010) and is effective in helping their staff stay in work (80\% in 2010) was fairly high, as was agreement that it is effective in helping improve their employees' mental health (e.g. $72 \%$ in 2010). A smaller but again unchanging proportion agreed that the policy was primarily designed to help their organisation avoid litigation, e.g. $42 \%$ in 2010.

\section{Preparedness for workplace mental health problems}

Some measures of employee stress levels appeared to be used increasingly over each year assessed and the overall time period (Table 2), including formal one-to-one (for $2010 v .2006$, adjusted OR 2.4, 95\% CI 1.8-3.2) and informal meetings with employees (for 2010 v. 2006, adjusted OR 3.1, 95\% CI 2.3-4.2). Assessments of absenteeism increased only between 2009 and $2010\left(\chi^{2}(1)=99.2\right.$, $P \leqslant 0.001)$. The use of consultants to evaluate stress levels did not increase at any time point or over the whole period. The proportion of respondents saying they used no measures fell to just 3\% (for 2010 v. 2006, adjusted OR 0.1, 95\% CI 0.1-0.2). When asked what preventive measures their companies used to minimise stress and its impact in the workplace, significantly more of those interviewed in 2010 compared with 2009 and 2006 reported auditing employees' stress levels (v. 2006, adjusted OR $1.8,95 \%$ CI 1.2-2.8); in contrast there had been no increase in the use of staff surveys to track well-being at work. Access to 
Table 1 Knowledge of mental health in the workplace

\begin{tabular}{|c|c|c|c|c|c|c|c|}
\hline & \multicolumn{3}{|c|}{$\begin{array}{l}\text { Percentage of interviewees responding positively } \\
\text { (adjusted percentage from model) }\end{array}$} & \multirow{2}{*}{$\begin{array}{l}\text { Adjusted odds ratio } \\
\text { for } 2010 \text { unless otherwise } \\
\text { specified, OR }(95 \% \mathrm{Cl})\end{array}$} & \multirow{2}{*}{$\begin{array}{l}\text { Multiple testing } \\
\text { adjusted } \\
\text { significance }\end{array}$} & \multicolumn{2}{|c|}{$\begin{array}{l}2009 \text { v. } 2010 \\
\text { adjusted }\end{array}$} \\
\hline & 2006 & 2009 & 2010 & & & $\chi^{2}$ & $P$ \\
\hline \multicolumn{8}{|l|}{$\begin{array}{l}\text { What specific disorders do you think } \\
\text { of when you hear the term 'mental } \\
\text { ill health in the workplace'? }\end{array}$} \\
\hline Anxiety & $2.3(2.6)$ & $13.1(11.2)$ & $12.6(10.8)$ & $4.60(2.40-8.84)$ & Sig. & 0.06 & 0.81 \\
\hline Depression & $21.7(23.5)$ & $46.8(45.1)$ & $49.2(47.5)$ & $2.94(2.21-3.93)$ & Sig. & 0.58 & 0.44 \\
\hline Manic depression/bipolar disorder & $1.5(1.8)$ & $8.0(5.4)$ & $6.4(4.3)$ & $2.48(1.09-5.67)$ & NS & 0.83 & 0.36 \\
\hline Stress & $45.9(49.1)$ & $52.0(50.4)$ & $60.4(58.9)$ & $1.49(1.14-1.94)$ & NS & 7.23 & 0.007 \\
\hline Substance abuse & $0.4(0.4)$ & $2.0(1.9)$ & $2.4(2.3)$ & $6.07(1.29-28.47)$ & NS & 0.19 & 0.66 \\
\hline Obsessive-compulsive disorder & $0.4(0.4)$ & $1.4(1.3)$ & $0.8(0.7)$ & $1.95(0.33-11.37)$ & NS & 0.80 & 0.367 \\
\hline Schizophrenia & $3.8(4.4)$ & $12.2(10.5)$ & $9.0(7.7)$ & $1.83(1.03-3.24)$ & NS & 2.59 & 0.11 \\
\hline Alzheimer's & $2.3(2.0)$ & $1.4(1.4)$ & $1.4(1.5)$ & $0.72(0.27-1.95)$ & NA & 0.00 & 0.99 \\
\hline Post-traumatic stress & $0.4(0.5)$ & $1.2(0.9)$ & $1.6(1.2)$ & $2.51(0.48-13.05)$ & NS & 0.31 & 0.57 \\
\hline Don't know & $31.4(25.8)$ & $17.9(18.8)$ & $13.2(13.8)$ & $0.46(0.33-0.64)$ & Sig. & 4.19 & 0.04 \\
\hline \multicolumn{8}{|l|}{$\begin{array}{l}\text { What percentage of your } \\
\text { employees do you think will have a } \\
\text { mental health problem at some }\end{array}$} \\
\hline \multicolumn{8}{|l|}{$\begin{array}{l}\text { Does your organisation currently } \\
\text { have any employees that you know }\end{array}$} \\
\hline $\begin{array}{l}\text { Employees suffering from stress are } \\
\text { able to work effectively }\end{array}$ & $43.0(45.0)$ & $46.6(45.6)$ & $43.6(42.5)$ & $0.90(0.69-1.18)$ & NA & 0.94 & 0.33 \\
\hline \multicolumn{8}{|c|}{$\begin{array}{l}\text { NA, not applicable; NS, not significant; sig., significant. } \\
\text { a. Ordinal logistic regression model. Statistic reported is the odds of recording a higher percentage category compared with the category below, excluding } 161 \text { participants who } \\
\text { recorded 'don't know'. } \\
\text { b. Multinomial logistic regression model. Statistic reported is a relative risk ratio given for the response 'yes' } v \text {. 'no' where the third category was 'don't know'. }\end{array}$} \\
\hline
\end{tabular}

counselling increased significantly from 2006 to 2009 (adjusted OR 1.7, 95\% CI 1.2-2.2) and again from 2009 to 2010 $\left(\chi^{2}(1)=10.0, \quad P=0.001\right)$. Although flexible holiday policies appeared to have increased from 2009 to $2010\left(\chi^{2}(1)=24.0\right.$, $P<0.001)$, there was no change for the period as a whole. Similarly, although there was no change over the whole period in the reported extent of management training on work-related stress, there is a suggestion that this increased from 2009 to 2010 - adjusted percentages were 34\% (95\% CI 30-39) for 2009 and $44 \%$ (95\% CI 39-48) for 2010, $\chi^{2}(1)=5.9, P=0.01$. However, practices to promote well-being (e.g. access to a gym) increased over each time period and as a whole (odds ratio for a positive response in 2010 v. 2006 was 2.3, 95\% CI 1.7-3.1).

Compared with 2006, employers in 2010 were more likely to respond affirmatively that their company had reduced someone's workload or hours (adjusted OR 3.2, 95\% CI 1.7-5.8), had provided increased supervision (adjusted OR 2.3, 95\% CI 1.3-3.9) or provided access to counselling (adjusted OR 1.8, 95\% CI 1.03.1). Adjustments to role had not changed over the whole period but increased between 2009 and $2010\left(\chi^{2}(1)=14.1\right.$, $P<0.001)$. There was no change in response to the question on providing the option to work from home. Few of those interviewed in each year reported having made none of the listed adjustments (Table 3 ).

Respondents were more likely to agree in 2009 that managers in their organisations had a good understanding of mental health issues (2009 v. 2006 adjusted OR 1.7, 95\% CI 1.3-2.3), but no overall increase was found for 2010. Responses to whether the organisation provided a good level of support for managers dealing with staff who had mental health problems also fell back between 2009 and $2010\left(\chi^{2}(1)=4.7, P=0.03\right)$ but were still higher at both later time points than in 2006 (adjusted OR for $2010 v$. 2006 was 1.8, 95\% CI 1.4-2.4). There was no significant change from 2009 to 2010 in the high proportions reporting they would feel comfortable talking about mental health issues with an employee ( $89 \%$ in 2010); at both time points respondents were more likely to agree with this compared with 2006 (e.g. for 2010 the adjusted OR was 1.9, 95\% CI 1.3-2.7) (Table 4). However, these figures are lower regarding job applicants (70\% in 2010) and there was no evidence for change over time. The intention to offer accommodations was consistently higher in 2009 and 2010 compared with 2006 (for 2010 adjusted OR 1.7, 95\% CI 1.3-2.4) but no further increase occurred after 2009.

\section{Attitudes of employers}

High proportions of those interviewed agreed that potential employees should disclose mental health problems prior to recruitment (e.g. $72 \%$ in 2010) and there was no change in the likelihood of response over time (Table 4). Although many of those interviewed also agreed that negative attitudes from co-workers were a major barrier to employing people with mental health problems, this was less likely in 2010 compared with 2006 (adjusted OR 0.5, 95\% CI 0.4-0.7) with the change occurring between 2009 and $2010\left(\chi^{2}(1)=11.0, P<0.001\right)$. Compared with respondents in 2006, those in both 2009 and 2010 were less likely to endorse the view that people with mental health problems were less reliable than other employees (2010 adjusted OR 0.6, 95\% CI 0.4-0.8) but there was no further change from 2009 to 2010. A small and declining proportion of respondents agreed that 'Employees who have been off work with a mental illness for more than a few weeks are unlikely to ever fully recover'; (for $2010 \mathrm{v}$. 2006, adjusted OR 0.5, 95\% CI 0.3-0.8). Higher proportions agreed that their organisations took a significant risk when employing people with mental health problems in public- or client-facing roles, but this was consistently less likely to be endorsed in both 2009 and 2010 compared with 2006 (for 2010, adjusted OR $0.6,95 \%$ CI $0.4-0.8$ ), with no further reduction from 2009 to 2010.

The majority of interviewees agreed that 'British industry loses a great deal of talent because it does not know how best to deal 
Table 2 Workplace policies relevant to mental health

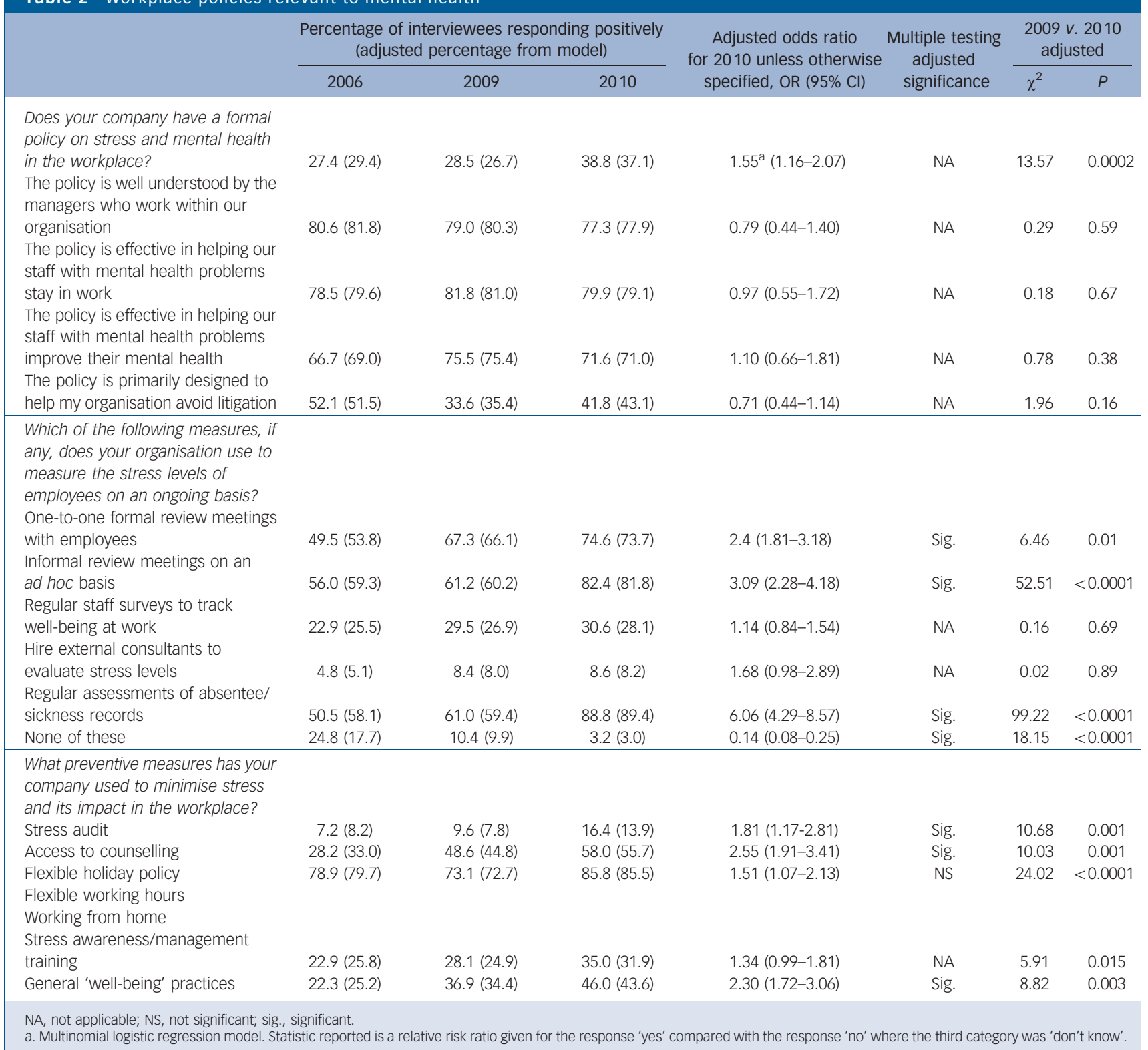

\begin{tabular}{|c|c|c|c|c|c|c|c|}
\hline & \multicolumn{3}{|c|}{$\begin{array}{l}\text { Percentage of interviewees responding positively } \\
\text { (adjusted percentage from model) }\end{array}$} & \multirow{2}{*}{$\begin{array}{l}\text { Adjusted odds ratio } \\
\text { for } 2010 \text { unless otherwise } \\
\text { specified, OR }(95 \% \mathrm{Cl})\end{array}$} & \multirow{2}{*}{$\begin{array}{l}\text { Multiple testing } \\
\text { adjusted } \\
\text { significance }\end{array}$} & \multicolumn{2}{|c|}{$\begin{array}{l}2009 \text { v. } 2010 \\
\text { adjusted }\end{array}$} \\
\hline & 2006 & 2009 & 2010 & & & $\chi^{2}$ & $P$ \\
\hline \multicolumn{8}{|l|}{$\begin{array}{l}\text { What accommodations have you } \\
\text { made for employees with mental } \\
\text { health problems? }\end{array}$} \\
\hline Reduced workload/working hours & $61.2(62.2)$ & $82.5(78.3)$ & $86.0(83.9)$ & $3.16(1.71-5.84)$ & Sig. & 1.65 & 0.20 \\
\hline Increased supervision & $45.9(45.1)$ & $55.6(54.4)$ & $66.1(65.4)$ & $2.29(1.34-3.91)$ & Sig. & 4.73 & 0.03 \\
\hline Adjustment to role & $64.7(64.9)$ & $64.3(59.1)$ & 80.1 (77.9) & $1.21(0.75-1.95)$ & NA & 14.09 & 0.0002 \\
\hline Access to counselling & $51.8(52.2)$ & $66.1(57.2)$ & $71.0(66.1)$ & $1.78(1.02-3.11)$ & NS & 2.69 & 0.10 \\
\hline Option to work from home & $23.5(24.0)$ & $39.8(33.0)$ & $46.2(41.1)$ & $1.56(0.85-2.91)$ & NA & 2.73 & 0.09 \\
\hline
\end{tabular}

with mental health in the workplace'; although respondents were more likely to endorse this view in 2009 compared with 2006 (adjusted OR 1.7, 95\% CI 1.3-2.3), a significant difference was not found in 2010. Similarly, respondents were more likely to endorse the view that British industry needs more support in improving the way it deals with mental health in the workplace in 2009 (adjusted OR 1.7, 95\% CI 1.2-2.4) compared with 2006 and also $2010\left(\chi^{2}(1)=6.5, P=0.01\right)$. 
Table 4 Attitudes to employees with mental health problems

\begin{tabular}{|c|c|c|c|c|c|c|c|}
\hline & \multicolumn{3}{|c|}{$\begin{array}{l}\text { Percentage of interviewees responding positively } \\
\text { (adjusted percentage from model) }\end{array}$} & \multirow{2}{*}{$\begin{array}{l}\text { Adjusted odds ratio } \\
\text { for } 2010 \text { unless otherwise } \\
\text { specified, OR }(95 \% \mathrm{Cl})\end{array}$} & \multirow{2}{*}{$\begin{array}{l}\text { Multiple testing } \\
\text { adjusted } \\
\text { significance }\end{array}$} & \multicolumn{2}{|c|}{$\begin{array}{l}2009 v .2010 \\
\text { adjusted }\end{array}$} \\
\hline & 2006 & 2009 & 2010 & & & $\chi^{2}$ & $P$ \\
\hline $\begin{array}{l}\text { I would feel comfortable talking } \\
\text { about mental health with my } \\
\text { employees }\end{array}$ & $78.5(80.2)$ & $91.4(91.2)$ & $88.6(88.3)$ & $1.86(1.29-2.69)$ & Sig. & 2.22 & 0.14 \\
\hline $\begin{array}{l}\text { I would feel comfortable talking } \\
\text { about mental health with job } \\
\text { applicants }\end{array}$ & $64.6(64.6)$ & $71.5(71.5)$ & $69.6(69.6)$ & $1.25(0.95-1.66)$ & NA & 0.44 & 0.50 \\
\hline $\begin{array}{l}\text { We would be flexible in offering } \\
\text { adjustments or accommodations to } \\
\text { someone with mental ill health }\end{array}$ & $68.6(74.5)$ & $87.3(86.8)$ & $84.2(83.5)$ & $1.72(1.25-2.38)$ & Sig. & 2.11 & 0.15 \\
\hline $\begin{array}{l}\text { Potential employees should } \\
\text { disclose mental health problems } \\
\text { prior to recruitment }\end{array}$ & $80.2(79.3)$ & $77.1(77.6)$ & $72.2(72.8)$ & $0.70(0.51-0.95)$ & NS & 3.15 & 0.07 \\
\hline $\begin{array}{l}\text { Negative attitudes from co-workers } \\
\text { are a major barrier to employing } \\
\text { people with mental health problems }\end{array}$ & $54.7(54.6)$ & $49.6(49.6)$ & $39.2(39.2)$ & $0.54(0.41-0.70)$ & Sig. & 10.95 & 0.0009 \\
\hline $\begin{array}{l}\text { People with mental health problems } \\
\text { are less reliable than other } \\
\text { employees }\end{array}$ & $32.2(28.8)$ & $18.3(19.1)$ & $18.6(19.4)$ & $0.60(0.44-0.81)$ & Sig. & 0.02 & 0.89 \\
\hline $\begin{array}{l}\text { Employees who have been off work } \\
\text { with a mental illness for more than } \\
\text { a few weeks are unlikely to ever } \\
\text { fully recover }\end{array}$ & $16.4(14.9)$ & $9.0(9.3)$ & $8.0(8.3)$ & $0.52(0.34-0.79)$ & Sig. & 0.29 & 0.59 \\
\hline $\begin{array}{l}\text { Organisations take a significant risk } \\
\text { when employing people with } \\
\text { mental health problems in a public/ } \\
\text { client-facing role }\end{array}$ & $49.1(46.1)$ & $35.3(36.5)$ & $31.6(32.8)$ & $0.57(0.43-0.75)$ & Sig. & 1.49 & 0.22 \\
\hline $\begin{array}{l}\text { British industry loses a great deal of } \\
\text { talent because it does not know } \\
\text { how best to deal with mental health } \\
\text { in the workplace }\end{array}$ & $67.0(69.7)$ & $80.5(79.8)$ & 76.2 (75.3) & $1.33(0.99-1.78)$ & NA & 2.75 & 0.10 \\
\hline $\begin{array}{l}\text { British industry needs more support } \\
\text { in improving the way it deals with } \\
\text { mental health in the workplace }\end{array}$ & $76.2(80.3)$ & $87.8(87.4)$ & $82.2(81.3)$ & $1.07(0.77-1.48)$ & NA & 6.53 & 0.01 \\
\hline
\end{tabular}

\section{Discussion}

The data present a mixed picture of several improvements, some improvements between 2006 and 2009 that have subsequently fallen back, and other variables showing no change. Starting with mental health knowledge, awareness of what constitutes a mental health problem has significantly improved, with far more recognition of common diagnoses in 2009 and 2010 compared with 2006. Additionally, there appears to be improved knowledge about the incidence and prevalence of mental health problems in the workplace. However, the majority of the employers interviewed continued to report that they did not know enough about the law regarding mental health in the workplace. This suggests that efforts to improve employers' legal knowledge in the area have not reached sufficient numbers of employers effectively. ${ }^{6,9,10}$ Further, the extent to which employers and managers believe that employees suffering from stress can work effectively remains unchanged.

Our findings suggest an increase in the existence of formal mental health policies and provision of workplace accommodations (i.e. actions specific to mental health), and increased implementation of policies not specific to but relevant to employees with mental health problems. Although the use of more costly methods of monitoring stress levels such as hiring consultants and conducting well-being surveys has not increased, lower-cost strategies such as meetings with employees have done so. Monitoring absenteeism has also increased recently although it cannot be assumed that the reason for doing so is to monitor workplace mental health. There have also been improvements in the proportion of employers who have a designated route for managing employees with mental health problems. Of those who do, a combination of internal human resources management and external resources such as the NHS or outsourced occupational health and employee assistance programmes was commonly used. There was no change regarding disclosure in job applications; over three-quarters of employers believed that people with mental health problems should disclose prior to employment, despite this having been made unlawful except in certain circumstances by the Equality Act $2010 .{ }^{12}$ However, not all employers would be comfortable actually discussing mental health with an applicant. This is consistent with the findings of Fenton et al that, depending on the size of the company, between half and three-quarters of companies never asked applicants about their mental health. ${ }^{13}$

\section{Limitations of the study}

Several study limitations must be considered. The most significant is our inability to assess the extent to which the changes observed during the study time interval were linked with the initiatives delivered by Time to Change. Awareness of Time to Challenge 
itself was low, at 7\% $(n=37)$ in 2009 and $4 \%(n=21)$ in 2010, compared with awareness of the Shaw Trust report of 2006 at $16 \%$ and $22 \%$ in 2009 and 2010 respectively. However, awareness of TTC through its social marketing campaign during the 2009 and 2010 time points is likely to have been similar to that for the general population (38-64\%; see Evans-Lacko et al, this supplement ${ }^{14}$ ), and therefore higher than either of these initiatives aimed at employers, but the relative impact of the social marketing campaign $v$. these targeted approaches is unknown.

The response rates of $71 \%$ for 2009 and $81 \%$ for 2010 were lower than that of $93 \%$ for the 2006 survey, so the later data may be less representative of British businesses as a whole. We have no data on the firms that refused to participate and therefore do not know whether the samples in 2009 and 2010 were less representative than that in 2006. The difference in rates most probably occurred because the Business Omnibus Survey (used in 2006) is well known among employers and has an exceptionally high response rate. The response rates obtained in 2009 and 2010 were similar to, if not higher than, response rates obtained during other surveys of businesses and professionals, ${ }^{15-17}$ implying that the survey's focus on mental health was unlikely to be negatively influencing participation and may even have had a positive effect. Should this be the case, it is possible that individuals choosing to take part in the survey might be more aware of mental health issues within the workplace than those declining, potentially having a small influence on the results. Further, we have no information on whether the response rate varied depending on the respondent's position within the company, but research suggests that top management are least likely to respond to telephone surveys, ${ }^{18}$ and this may have affected the results. Finally, when discussing their company's policy on mental ill health, respondents provided their subjective opinions rather than any objective measure. The survey examines the opinions of senior company executives who may have very different views from those of their middle managers, whereas these line managers have a stronger and more direct influence on the day-to-day working life of employees with mental health problems.

\section{Interpretation}

This survey revealed encouraging improvements in employers' awareness of common mental health problems, their attitudes toward employing people with mental health problems, and their reported behaviour in terms of preventing and managing mental ill health in the workplace between 2006 and 2010. These improvements occurred against a backdrop of economic recession when it might be expected that attitudes and behaviour towards people who might need workplace accommodations would deteriorate. ${ }^{19}$ The consistency of improvements across the domains of knowledge, attitudes and behaviours is important, because (for example) increasing mental health literacy alone does not necessarily correlate with improvements in the emotional response to the issue. ${ }^{20,21}$ However, Manning \& White found that discrimination varied depending on a person's diagnosis, ${ }^{22}$ suggesting that even if better awareness of depression and anxiety did lead to an improved response among employers towards people with such problems, it might not predict an improved response to people with less common diagnoses. In terms of employers' attitudes, they are now less likely to perceive employing people with mental health problems as a risk with respect to their reliability, working directly with customers or in terms of their colleagues' reactions to them. The change in expectations about colleagues' reactions suggests that employers discern a difference in their employees' attitudes and is particularly marked between 2009 and 2010, consistent with the improvement in public attitudes to mental illness over this period. ${ }^{23}$ Measures such as absentee monitoring or allowing working from home might be introduced primarily for reasons other than to accommodate people with mental health problems. However, the positive changes in reported behaviour over 20092010 are again consistent with other findings, in this case from the Viewpoint survey of mental health service users' experience of discrimination in finding or keeping employment. ${ }^{24}$

\section{Implications for research}

Further research examining the motivations behind the changes in workplace practices would be helpful in interpreting these findings. It is important to continue to monitor the impact of government and non-governmental initiatives not just by monitoring employers' knowledge, attitudes and behaviour, but also by assessing rates of employment among people with mental health problems in comparison with people with physical or intellectual disabilities. ${ }^{25}$

\section{Implications for policy}

With respect to existing employees, there is clear evidence that additional guidance regarding (for example) legislation relevant to mental health problems would be well received by employers. This may reflect increasing awareness of the importance of workplace mental health. With respect to potential employees, the finding that three-quarters of employers wish people to disclose mental health problems prior to employment suggests considerable resistance to the Equality Act 2010, which makes it unlawful to ask candidates pre-employment health questions except under certain circumstances. ${ }^{12}$ It is important to ensure that employers are aware of the Act in this respect, and to provide legal advice for people who are unsure whether to disclose their illness, who might have experienced discrimination, or who need to know whether or not they are covered by the Act and can therefore request reasonable accommodations.

Claire Henderson, PhD, Paul Williams, MSC, Kirsty Little, PhD, Graham Thornicroft, PhD, Health Service and Population Research Department, King's College London, Institute of Psychiatry, London, UK

Correspondence: Dr Claire Henderson, Health Service and Population Research Department, Box PO29, Institute of Psychiatry, De Crespigny Park, London SE5 8AF, UK. Email: Claire.1.Henderson@kcl.ac.uk

\section{Funding}

The study was part funded by the Big Lottery Fund, Comic Relief and Shifting Attitudes to Mental Illness (ShiFT), UK Department of Health, through their funding of the Time to Change programme. The study was also supported by the National Institute for Health Research (NIHR) Applied Programme grant awarded to the South London and Maudsley National Health Service (NHS) Foundation Trust (RP-PG-0606-1053). G.T. is funded in relation to a NIHR Applied Programme grant awarded to the South London and Maudsley NHS Foundation Trust and the NIHR Specialist Mental Health Biomedical Research Centre at the Institute of Psychiatry, King's College, London. C.H. is also funded by a grant from Guy's and St Thomas' Charity, a grant from the Maudsley Charity and an NIHR Programme Grant for Applied Research awarded to Camden and Islington NHS Foundation Trust.

\section{Acknowledgements}

We thank Paul Flatters of the Trajectory Partnership for information on the 2006 survey and advice on repeating it in 2009 and 2010. This study was carried out as a collaboration between the Shaw Trust and the National Institute for Health Research Specialist Mental Health Biomedical Research Centre at the Institute of Psychiatry, King's College London and the South London and Maudsley National Health Service Foundation Trust. We thank and the South London and Maudsley National Health Service Foundation Trust. We thank
sue Baker, Maggie Gibbons and Paul Farmer of Mind and Paul Corry and Mark Davies of Rethink Mental Illness for their collaboration. 


\section{References}

1 Health and Safety Eexecutive. Self-Reported Work-Related IIIness and Workplace Injuries in 2007/08: Results From the Labour Force Survey. HSE, 2008.

2 Pattani S, Constantinovici N, Williams S. Who retires early from the NHS because of ill health and what does it cost? A national cross sectional study. BMJ 2001; 322: 208-9.

3 Shaw Trust. Mental Health: The Last Workplace Taboo. Shaw Trust, 2006 (http://www.shaw-trust.org.uk/files/st_mental_health_full.pdf).

4 Chandola T. Stress at Work. British Academy, 2010.

5 Lelliot P, Tulloch S, Boardman J, Harvey S, Henderson M, Knapp M. Mental Health and Work. Royal College of Psychiatrists, 2009

6 Shifting Attitudes to Mental Illness. Line Managers' Resource. SHiFT, 2010 (http://www.shift.org.uk/employers/).

7 Centre for Mental Health. Employment and mental health: issue overview. 2012 (http://www. centreformentalhealth.org.uk/employment/ issue_overview.aspx).

8 Mind Out for Mental Health. Line Managers' Resource: A Practical Guide to Managing and Supporting Mental Health in the Workplace. 2008 (http:// www.mindfulemployer.net/Line\%20Managers\%20Resource.pdf).

9 Mind. Time to Change. Time to Challenge. Mind, 2012 (http://www.mind. org.uk/campaigns_and_issues/time_to_change/time_to_challenge).

10 Little K, Henderson C, Brohan E, Thornicroft G. Employers' attitudes to people with mental health problems in the workplace in Britain: changes between 2006 and 2009. Epidemiol Psychiatr Sci 2011; 20: 73-81.

11 Continental Research. Business Omnibus Survey. Continental Research, 2009 .

12 Lockwood G, Henderson C, Thornicroft G. The Equality Act 2010 and mental health. Br J Psychiatry 2012; 200: 182-3.
13 Fenton J, O'Hanlon D, Allen D. Does having been on a 'section' reduce your chances of getting a job? Psychiatr Bull 2003; 27: 177-8.

14 Evans-Lacko S, Malcolm E, West K, Rose D, London J, Rüsch N, et al. Influence of Time to Change's social marketing interventions on stigma in England 2009-2011. Br J Psychiatry 2013; 202 (suppl 55) s77-88.

15 Brosseau L, Li S. Small business owners' health and safety intentions: a cross-sectional survey. Environm Health 2005; 4: 23.

16 Day $\mathrm{T}$, Challen $\mathrm{K}$, Walter $\mathrm{D}$. Major incident planning in primary care trusts in north-west England: a cross-sectional survey. Health Serv Manage Res 2010; 23: 25-9.

17 Dennis J. Raising response rates in mail surveys of small business owners: results of an experiment. J Small Business Management 2003; 41: 278-95.

18 Baruch Y. Response rate in academic studies - a comparative analysis. Human Relations 1999; 52: 421-38.

19 Warner R. Recovery from Schizophrenia: Psychiatry and Political Economy. Brunner-Routledge, 2004

20 Angermeyer MC, Holzinger A, Matschinger $\mathrm{H}$. Emotional reactions to people with mental illness. Epidemiol Psichiatr Soc 2010; 19: 26-32.

21 Pescosolido BA, Martin JK, Long JS, Medina TR, Phelan JC, Link BG. 'A disease like any other'? A decade of change in public reactions to schizophrenia, depression, and alcohol dependence. Am J Psychiatry 2010; 167: 1321-30.

22 Manning C, White PD. Attitudes of employers to the mentally ill. Psychiatr Bull 1995; 19: 541-3.

23 TNS UK for the National Mental Health Development Unit. Attitudes to Mental IIIness 2010. Department of Health, 2010.

24 Henderson C, Corker E, Lewis-Holmes E, Hamilton S, Flach C, Rose D, et al. Reducing mental health related stigma and discrimination in England: one year outcomes of the Time to Change Programme for service user-rated experiences of discrimination. Psychiatr Serv 2012; 63: 451-7.

25 Social Exclusion Unit. Mental Health and Social Exclusion. Office of the Deputy Prime Minister, 2004 